\title{
The Effect of the In-Situ Heat Treatment on the Martensitic Transformation and Specific Properties of the Fe-Mn-Si-Cr Shape Memory Alloys Processed by HSHPT Severe Plastic Deformation
}

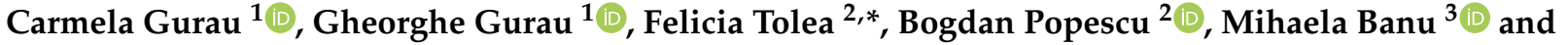 \\ Leandru-Gheorghe Bujoreanu ${ }^{4}$
}

check for

updates

Citation: Gurau, C.; Gurau, G.; Tolea, F.; Popescu, B.; Banu, M.; Bujoreanu, L.-G. The Effect of the In-Situ Heat Treatment on the Martensitic Transformation and Specific Properties of the Fe-Mn-Si-Cr Shape Memory Alloys Processed by HSHPT Severe Plastic Deformation. Materials 2021, 14, 4621.

https://doi.org/10.3390/ma14164621

Academic Editor: Tatyana Koutzarova

Received: 28 June 2021

Accepted: 12 August 2021

Published: 17 August 2021

Publisher's Note: MDPI stays neutral with regard to jurisdictional claims in published maps and institutional affiliations.

Copyright: (c) 2021 by the authors. Licensee MDPI, Basel, Switzerland. This article is an open access article distributed under the terms and conditions of the Creative Commons Attribution (CC BY) license (https:/ / creativecommons.org/licenses/by/ $4.0 /)$.
1 Faculty of Engineering, "Dunarea de Jos" University of Galati, Domneasca Street 47, 800008 Galati, Romania; Carmela.Gurau@ugal.ro (C.G.); Gheorghe.Gurau@ugal.ro (G.G.)

2 National Institute of Materials Physics, Atomistilor 405A, 077125 Magurele, Romania; bogdan.popescu@infim.ro

3 Department of Mechanical Engineering, University of Michigan, 2350 Hayward Street, Ann Arbor, MI 48109, USA; mbanu@umich.edu

4 Faculty of Materials Science and Engineering, The "Gheorghe Asachi" Technical University of Iasi, Blvd. Dimitrie Mangeron 61A, 700050 Iasi, Romania; leandru-gheorghe.bujoreanu@academic.tuiasi.ro

* Correspondence: felicia.tolea@infim.ro

\begin{abstract}
This work focuses on the temperature evolution of the martensitic phase $\varepsilon$ (hexagonal close packed) induced by the severe plastic deformation via High Speed High Pressure Torsion method in $\mathrm{Fe}_{57} \mathrm{Mn}_{27} \mathrm{Si}_{11} \mathrm{Cr}_{5}$ (at \%) alloy. The iron rich alloy crystalline structure, magnetic and transport properties were investigated on samples subjected to room temperature High Speed High Pressure Torsion incorporating 1.86 degree of deformation and also hot-compression. Thermo-resistivity as well as thermomagnetic measurements indicate an antiferromagnetic behavior with the Néel temperature $\left(\mathrm{T}_{\mathrm{N}}\right)$ around $244 \mathrm{~K}$, directly related to the austenitic $\gamma$-phase. The sudden increase of the resistivity on cooling below the Néel temperature can be explained by an increased phonon-electron interaction. In-situ magnetic and electric transport measurements up to $900 \mathrm{~K}$ are equivalent to thermal treatments and lead to the appearance of the bcc-ferrite-like type phase, to the detriment of the $\varepsilon(\mathrm{hcp})$ martensite and the $\gamma(\mathrm{fcc})$ austenite phases.
\end{abstract}

Keywords: severe plastic deformation; HSHPT; ferromagnetic shape memory alloy; martensitic transformation; Fe-Mn-Si-Cr; magnetic properties; transport properties

\section{Introduction}

The ability of some alloys to remember their shape at two different temperatures is called shape memory effect (SME), and the respective materials are referred to as shape memory alloys (SMAs). SME is governed by a non-diffusive first-order phase transformation called martensitic transformation (MT). During the MT the atoms move at distances smaller than the inter-atomic distances, and they go from an austenitic phase of high temperature and high symmetry (cubic type) to a martensitic phase of low temperature, with lower symmetry (tetragonal, orthorhombic, hexagonal). NiTi alloys, Cu-based and Fe-based alloys are the most well known types of SMAs. Based on their crystalline structure in the austenitic phase they are grouped in " $\beta$-type" with body centered cubic (bcc) cell structure, a subclass of them being Ni-Ti [1], Co-Ni-Ga [2-4], Cu-Zn-Al, $\mathrm{Cu}-\mathrm{Al}-\mathrm{Ni}$ [5] and Ni-Mn-Ga [6-8], Ni-Fe-Ga Heusler alloys [8,9] and " $\gamma$-type", with face centered cubic (fcc) cell structure, comprising Fe-Mn and Fe-Mn-Si [10,11], FePd [12] or FeNiCoTi [13]. Among these, Fe-Mn shape memory alloys present a good workability, weldability, corrosion resistance [14], large damping effect [15], recovery strain due to the shape memory effect (SME) [16] and superelasticity [17,18]. It has been shown that addition of 
$\mathrm{Si}$ atoms enhances reversibility of martensite and the shape memory effect in the Fe-Mn alloys [16], while the $\mathrm{Cr}$ addition (between 5 and $9 \mathrm{wt} . \%$ ) improves the corrosion resistance of Fe-Mn-Si alloys [19]. The MT of Fe-Mn-Si alloys shows a particular non-thermoelastic stress-induced $\gamma-\varepsilon$ martensitic transformation and its $\varepsilon-\gamma$ reverse transformation during subsequent heating [10,11,14-21]. Additionally, beside $\varepsilon$-martensite (hexagonal close packed-hcp—stress-induced structure), the $\alpha^{\prime}$-martensite (body-centred-tetragonal—bctstructure) may appear at the intersections of crystallographic defects induced by plastic deformation such as mechanical twins, stacking faults and shear bands [22,23]. In addition, according to [11], the $\alpha^{\prime}$-martensite can be formed in the stress-induced $\varepsilon$ martensite, in a probable $\gamma-\varepsilon-\alpha^{\prime}$ transformation, with the $\varepsilon$-martensite acting as an intermediate phase for $\alpha^{\prime}$-formation [23].

In the recent years, material properties design garnet high interest and consequently, the relationship between the process parameters and material properties requires more understanding. For example, it is not fully known which are the physical processes occurring during severe plastic deformation (SPD) of solid state materials which lead to significant changes of the typical properties of the raw material [24-29]. Thus, numerous methods of SPD have been developed to refine the microstructures of SMAs [30]. The possibility to control the grains size through SPD opens an opportunity to control the $\gamma-\varepsilon$ martensitic transformation in shape memory ferrous alloys. Studies show that the ultrafine grained iron based SMAs exhibit excellent recoverable strain, being more beneficial in the long-term engineering applications [26,31]. Our previous work on Fe-28Mn-6Si-5Cr (wt.\%) SMA also show that an (ultra)fine structure is obtained when the samples are subjected to SPD via high speed high pressure torsion (HSHPT) technique [32,33]. In contrast with most well known SMAs (NiTi and $\mathrm{Cu}$ based) to which the shape recovery is due to two-way martensitic transformation, hinge on ordered lattice structure, the Fe-Mn-Si SMAs are characterized by disordered lattice and a dislocation-assisted transformation mechanism [34].

The current work investigates on how the SPD in particular High Speed High Pressure Torsion (HSHPT) process influences the magnetic behavior of $\mathrm{Fe}_{57} \mathrm{Mn}_{27} \mathrm{Si}_{11} \mathrm{Cr}_{4}$ at \% shape memory alloy during ultrafine microstructure development. The microstructure of the materials is investigated with emphases on the stacking faults, twinning and dislocation density in austenite, and correlated to the thermo-magnetic and transport properties. The results aim to extend the understanding of the application potential of SPD to the economically attractive iron based SMAs. Potential applications include pipe steel joints [35], fishplate for crane rail [35] or in constructions as dumping materials, where the stress induced $\varepsilon$ martensite and deformation twins occur and disappear by cyclic tensile and compressive deformation which absorbs vibrations.

\section{Material and Methods}

The $\mathrm{Fe}_{57} \mathrm{Mn}_{27} \mathrm{Si}_{11} \mathrm{Cr}_{4}$ at \% SMA ingots were obtained by melting the elements in a Fives Celes induction furnace MP25 (Lautenbach, France). Before the SPD processing, circular crowns billets were cut out of the drilled ingots. In order to obtain ultra-fine grained samples via HSHPT process, three deformation parameters were adjusted: the rotation speed of the superior punch $\left(\sim 1.0 \times 10^{3} \mathrm{rpm}\right)$, the compression force at about $\sim 1 \mathrm{GPa}$ and the concurrent friction occurring between the punches and the sample (caused by the high pressure on the bottom anvil and to relative displacement of the sample-lower anvil). A lubricated billet was placed between the anvils. The specimens were initially pressed at $5 \mathrm{MPa}$ at room temperature (RT). The resulted HSHPT processed specimens, under an applied pressure of about $1 \mathrm{GPa}$ and 1.86 strain level (sample denoted C), are truncated cone-modules of $\sim 30 \mathrm{~mm}$ in diameter, and $0.2 \mathrm{~mm}$ in thickness. The extent of deformation degree was estimated using the logarithmic relationship:

$$
\varepsilon=\ln \left(h_{i} / h_{f}\right)
$$


where $h_{i}$ and $h_{f}$ indicate initial and final thickness of the sample, respectively. The applied rotation speed of the upper piston was $1794 \mathrm{rpm}$. The duration of the process was around $10 \mathrm{~s}$. After severe plastic deformation the conical SMA modules were pressed back into disk shapes. Further, thermo-mechanical cycles of simultaneous compression and heating at $450{ }^{\circ} \mathrm{C}$ were applied to improve the super-elastic properties of the modules (denoted $\mathrm{TC}$ ). The processing pathway of the samples is presented in the schematic diagram of the experiment from Figure 1.

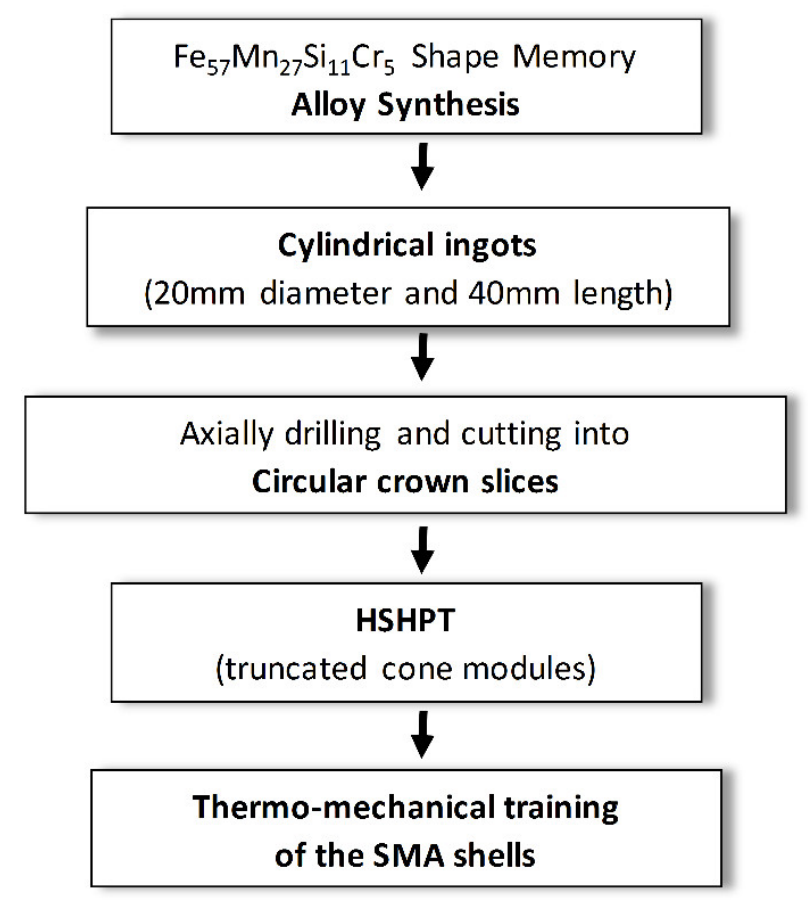

Figure 1. Schematic diagram of the experiment.

All the subsequent investigations were carried out on samples taken from the peripheral area of the truncated shells (see Figure 2).

The chemical composition was performed using SPECTRO XEPOS 03 energy dispersive X-ray fluorescence (ED-XRF) spectrometer manufactured by SPECTRO Analytical Instruments $\mathrm{GmbH}$, Kleve, Germany. The microstructure of the samples was studied by transmission electron microscopy (TEM) using a JEOL 2010F microscope (JEOL, Peabody, MA, USA) operated at $200 \mathrm{kV}$, with STEM mode. TEM specimens were ion milled using a Helios 650S instrument (Thermo Fisher Scientific, Waltham, MA, USA). Observations were made in bright field imaging modes. The samples for TEM investigations were taken perpendicularly to the surface of severe plastic deformation of the modules. Annular dark-field (ADF) was employed to improve grain visibility. The average grain size was calculated using ADF images and averaging the intersect lengths over 500 grains in different areas of the images. The crystalline structure was investigated by $\mathrm{X}$-ray diffraction at RT using a Bruker AXS D8 Advance diffractometer $(\mathrm{Cu} \mathrm{K} \alpha$ radiation) manufactured by Bruker, Hamburg, Germany), within the representative region of $2 \theta$ between $40^{\circ}$ and $85^{\circ}$, in the Bragg-Brentano geometry. The phase transformation temperatures were determinate by differential scanning calorimetry (DSC using Netzsch 204 F1 Calorimeter, Selb, Germany, with Proteus Software 2007) with a scanning rate of $20 \mathrm{~K} / \mathrm{min}$ and $10 \mathrm{~K} / \mathrm{min}$. The low temperature magnetic measurements below $350 \mathrm{~K}$ were performed with a Quantum Design-Superconducting Quantum Interference Device (SQUID) magnetometer in Reciprocal Space Option (RSO mode) in the temperature range from $4 \mathrm{~K}$ up to $390 \mathrm{~K}$, manufactured in San Diego, CA, USA. The high temperature magnetic properties were estimated using the oven module of the Quantum Design-Physical Properties Measurement System (PPMS) - in Vibrating Sample Magnetometry (VSM) mode, manufactured 
in San Diego, CA, USA. The temperature and field-dependent resistivity in low and high temperature range were analysed in order to characterize the electrical transport of samples. These investigations were carried out in standard four-probe method (silver paste was used to make the contacts) using transport option of PPMS. The measurements have been carried out with the current along the longitudinal direction of samples, the magnetic field perpendicular to the samples.
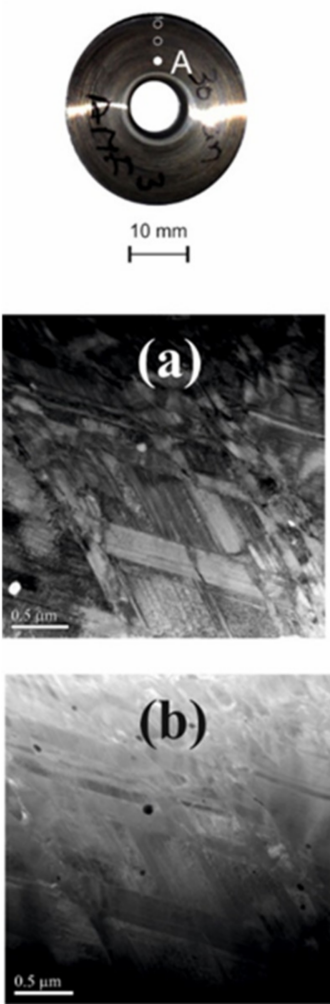
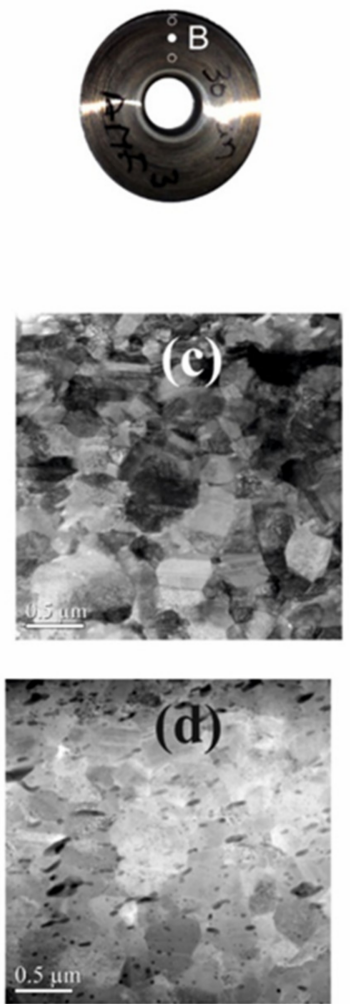
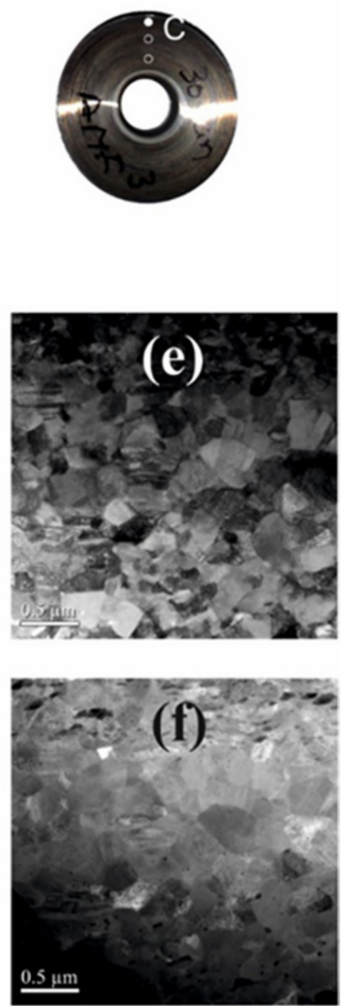

Figure 2. Truncated shells after HSHTP in three different radial areas, and the corresponding TEM and ADF micrographs grouped as follows: area $(\mathbf{A})(\mathbf{a}, \mathbf{b})$, area $(\mathbf{B})(\mathbf{c}, \mathbf{d})$ and area $(\mathbf{C})(\mathbf{e}, \mathbf{f})$.

Noteworthy, the magnetic and electric transport measurements were performed up to $970 \mathrm{~K}$ (high temperature) in controlled atmosphere, equivalent to an in situ thermal treatment which influences the constituent crystalline phases of the samples. For this reason, these samples are denoted further HC (for sample C after high temperature investigations) and HTC (for high temperature investigated TC sample).

\section{Results and Discussion}

\subsection{TEM Observations}

SMA modules were analyzed to understand the influence of the HSHPT processing on microstructural features visible under TEM. TEM observations enable characterization of the grain size and morphology, and they are important data for explaining the shape memory alloy behavior post SPD processing. Figure 2 shows the TEM and ADF micrographs observed on the cone generator, from the three distinct radially distributed areas, denoted A, B and C, respectively.

The three analysed areas shown microstructural differences caused by the non-uniform severe plastic deformation of each region. Figure 2a shows TEM micrograph of the central part of the module where bands of martensite plates alongside stacking faults (Sfs), oriented mainly on two directions, can be identified. As it is already known, the fcc-to-hcp transformation process is promoted by gliding of multiple Shockley partials of $1 / 6$ fcc type on alternate $\{111\}$ fcc planes that depends on crystal orientation [34]. The stacking fault energy (SFE) of these alloys is lower than $20 \mathrm{~mJ} / \mathrm{m}^{2}$ with consequences on the sus- 
ceptibility to nano-sized twins in the microstructure. The gliding of Shockley partials that induce the $\gamma-\varepsilon$ martensitic transformation depends on crystal orientation. Certain crystallographic textures in polycrystals will contribute to a better shape recovery at lower applied stresses [26]. It is well known that various factors are involved in the grain refinement of SPD-processed metals such as the intrinsic characteristics of material, the true strain, the temperature of deformation. In addition, it was reported that the grain size obtained in the SPD process of fcc materials is closely related to SFE value. A low value of $\gamma$ SFE (below $20 \mathrm{~mJ} / \mathrm{m}^{2}$ ), indicates a lower average grain size [36]. As a result of the HSHPT deformation, typical HCP stress-induced $\varepsilon$-martensite plates formed as parallel stacks of fine bands. In addition, a small amount of phase, $\alpha^{\prime}$ martensite, as little particles with tangle shape were distinguished (Figure 2a,b and the high magnification bright field TEM image from area A seen in Figure 3) at intersections in the $\varepsilon$-martensite due to the mutual dislocation reaction of different martensitic shear systems [37]. The formation of the $\alpha^{\prime}$ martensite crystals has been established to be mainly associated with dislocations in the prior austenite phase and they appear in dislocated austenite areas [26,38,39].

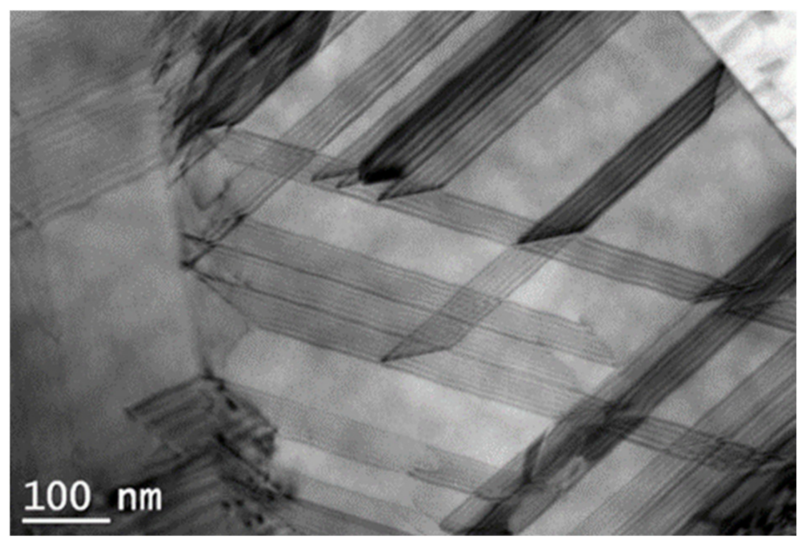

Figure 3. Stacking faults observed in the iron-based modules—processed by HSHPT (sample C).

In the $B$ and $C$ areas forming of martensite crystals among the austenite grains is noticed (as shown in Figure 3). The $\varepsilon$-martensite that appear inside the grain boundaries as fine parallel stripes is considered a prerequisite for the SME. In addition, frequently, the appearance of two or three martensite variants are reported within parent austenitic grains in the $\mathrm{Si} \geq 4 \mathrm{wt}$ \% alloys [37]. Plastic deformation of low SFEs Fe-Mn-Si based SMAs involves formation of stacking faults, mechanical twins, and shear bands [29]. In these B and $C$ areas of the samples, ultra-fine austenitic grains are observed as a result of stronger compression and rotation during HSHTP process (Figure $2 \mathrm{c}-\mathrm{f}$ ). The average grain size in the $B$ and $C$ areas are determined by the linear-intercept method. In the middle (B) area of disk the average of austenitic grains is about $210 \mathrm{~nm}$, while at the edge of the sample (C) the average grain size is under $190 \mathrm{~nm}$. However, the values of the grain size in both areas are ranging between $10 \mathrm{~nm}$ and $500 \mathrm{~nm}$. Within the ultra-fine $\gamma$ grains the $\varepsilon$ martensite stripes, under $50 \mathrm{~nm}$ wide, are visible. In the $C$ region, the TEM micrograph shown in Figure 3, reveals extended parallel stacking faults with hcp structure type formed as a result of deformation by HSHPT.

\subsection{The Mechanical Properties of Ultra-Fine Structured Fe-Mn-Si-Cr Alloy}

The elastic properties in Fe-Mn based alloy are related to a disordered distribution of magnetic moment [40]. The deformation induced by HSHTP promotes the refinement of the grain size, with an average under $200 \mathrm{~nm}$, distributed on samples radius and contributes also to the enhancement of the SME. The curves obtained during the compression loading/unloading cycle of the analyzed truncated modules are shown in Figure 4. They suggest a "super-elastic" behavior showing a 92.85\% recovery after deformation. 


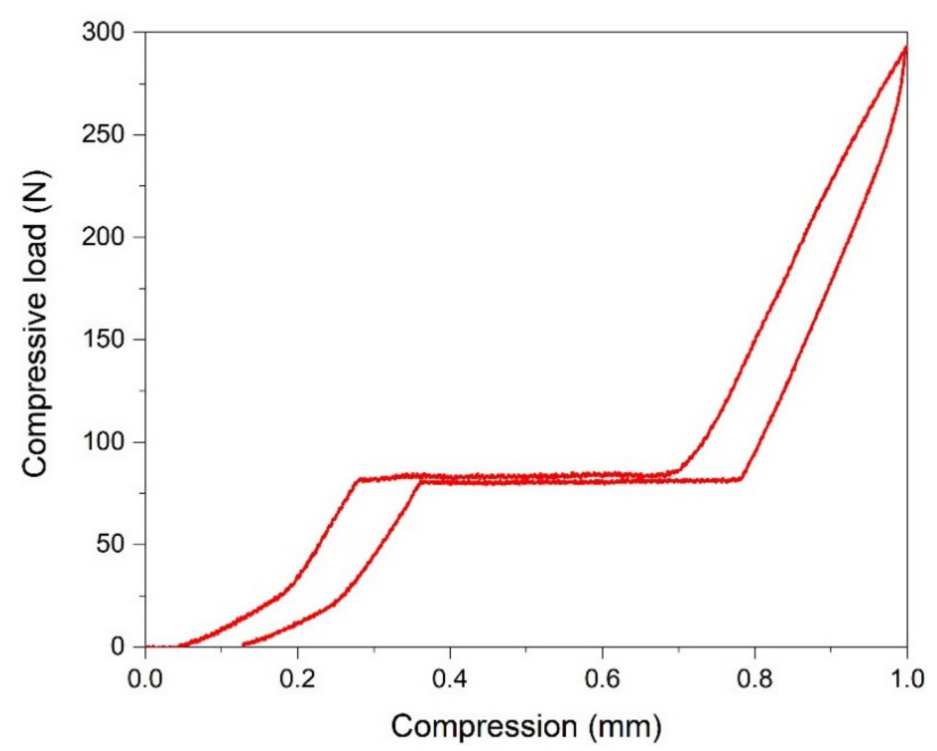

Figure 4. The shape memory response of Fe-Mn-Si-Cr SMA modules manufactured by HSHPT obtained during the compression loading/unloading cycles.

\subsection{XRD Results}

The X-ray diffraction analysis was performed in the bulk state, on HSHPT'ed modules. Prior to XRD, etching was used to remove the oxidation of the surface layer and the regions affected by the cutting process. XRD investigations support the TEM observations showing that the SPD samples (C and TC) consist of the parent austenite $\gamma$ phase (Fm-3m, no. 225), the deformation induced $\varepsilon$ martensite phase (P63/mmc, no. 194) and traces of $\alpha^{\prime}$ martensite (I $m-3 m$, no. 229) (see Figure 5). However, after applying the in situ thermal treatment at $970 \mathrm{~K}$ the phase composition changes dramatically, with an $\delta$-ferrite (bcc) [19] phase evolving toward becoming the dominant phase in both HC and HTC samples. Small amounts of the secondary phases, $\gamma$ (fcc) and $\varepsilon$ (hcp), are still detected in the HC sample, while through analysing the diffraction patterns of the HTC sample it can be counted a very weak contribution of the diffraction lines of the $\gamma$ austenite. Our findings on the presence of second phases agree with the reports on FeMnSi-based systems, widely discussed in the literature [19]. A detailed structural analysis is beyond the scope of this study but also not possible due to the surface quality and the quantity of the samples resulted after the SPD, and moreover due to the samples hardness which prevented the obtaining of powders for an optimal diffraction experiment. Nevertheless, the information gathered about phase composition of the samples correlates with the magnetometry outcome, detailed in a further paragraph, and is vital in understanding those results. 


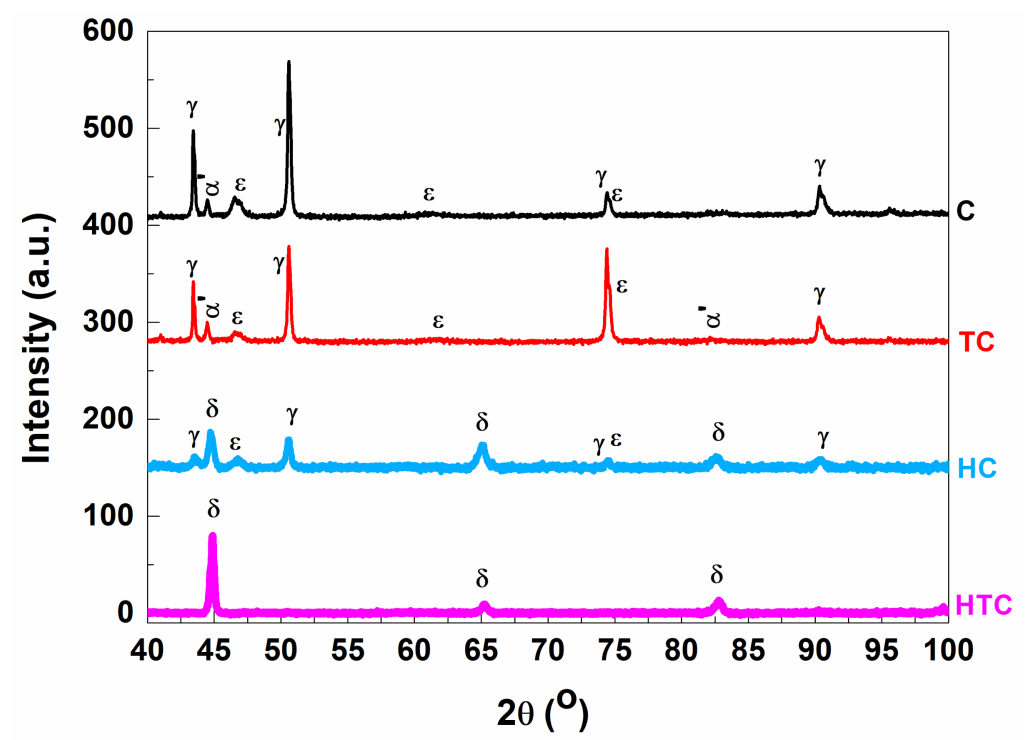

Figure 5. XRD patterns showing phase composition of $\mathrm{C}$ and $\mathrm{TC}$ alloys, and their evolution after the in situ heat treatment at $975 \mathrm{~K}$.

\subsection{DSC Results}

DSC measurements performed in a temperature range between $300 \mathrm{~K}$ and $950 \mathrm{~K}$ show the reverse behavior of MT for $\mathrm{C}$ and TC samples (Figure 6a, respectively, $\mathrm{b}$ ) during the heating with $20 \mathrm{~K} / \mathrm{min}$ and, respectively, with $10 \mathrm{~K} / \mathrm{min}$, in a protective He atmosphere.
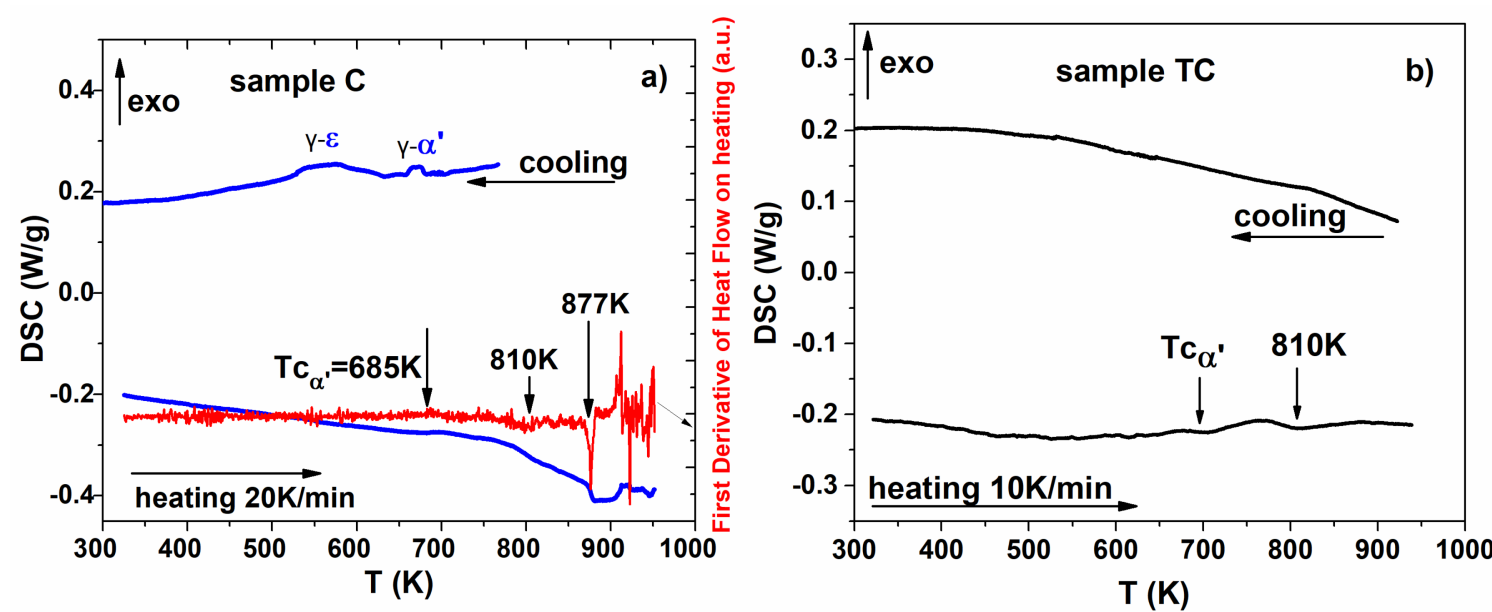

Figure 6. DSC scans versus temperature on heating and cooling for (a) sample C and (b) sample TC.

On heating, the sample $C$ show an inflexion around $685 \mathrm{~K}$, attributed to the Curie temperature of the $\alpha^{\prime}$ phase, which may be associated with the temperature dependence of the magnetization at high temperatures (see High Temperature Thermo-Magnetic Measurements subsection). By further heating of the sample, a wide and complex endothermal peak appears which can be better explained by a correlation with the magnetization data $\mathrm{M}(\mathrm{T})$ and $\mathrm{dM} / \mathrm{dT}$ (from High Temperature Thermo-Magnetic Measurements subsection). This wide peak is generated by the $\alpha^{\prime}-\gamma$ transition (around $800 \mathrm{~K}$ ) due to the thermally activated atoms diffusion. When cooling back the sample, two other transformations $\varepsilon-\alpha^{\prime}$ and $\gamma-\varepsilon$ occur, observed in the RT XRD pattern of the HC sample. The reverse transformation of the $\varepsilon$ martensite back to austenite takes place in a wide temperature interval. In a similar study, [39] it was also found that on the heating curve double peaks attributed to the $\varepsilon-\gamma$ si $\alpha^{\prime}-\gamma$ transitions appear, in this order, while on cooling $\gamma-\alpha^{\prime}$ and $\gamma-\varepsilon$ can be identified. The transformation $\alpha^{\prime}-\gamma$ and $\gamma-\alpha^{\prime}$ is the one taking place at higher temperatures. 
A different behavior is observed for the TC sample. For example, at heating, DSC measurements show a Curie transition at $685 \mathrm{~K}$, and one endothermal peak at $810 \mathrm{~K}$. However, MT was not detected on cooling, because there are no $\gamma, \varepsilon, \alpha^{\prime}$ phases present in the XRD results (Figure 5). The differences between the transformation reported by us and those found in literature [41] arise from the processing method.

\subsection{Magnetic Behavior}

\subsubsection{Low Temperature Thermo-Magnetic Measurements}

Magnetic properties of Fe-Mn-Si-Cr alloys are sensitive to the Mn content [19,38-40], and also to the preparation route $[18,19,23,24,41]$. The alloys with high Mn content favour the $\varepsilon-\gamma$ martensitic transformation and order antiferromagnetically below the Néel temperature [20,42-46]. The temperature dependence of the magnetization depicted in Figure 7a reveals a change in slope at the Néel temperature, $\mathrm{T}_{\mathrm{N}}$, from negative in paramagnetic state to positive in antiferromagnetic state and is atributed to the austenitic $\gamma$-phase $[25,47-50]$. The $\mathrm{T}_{\mathrm{N}}$ values are rangeing between $244 \mathrm{~K}$ si $250 \mathrm{~K}$. The derivative of the magnetization, $\mathrm{dM} / \mathrm{dT}$, exhibit another Neel temperature $\mathrm{T}_{\mathrm{N}}$, aroud $50 \mathrm{~K}$, which may be associated with the HSHPT induced martensite. Our results for the Neel temperature $T_{N \gamma}$ is close to the one reported in [43-45] for a similar Mn content, while for $\mathrm{T}_{\mathrm{N \varepsilon}}$ our reported value is smaller than previously reported [44] $\left(\mathrm{T}_{\mathrm{N \varepsilon}}=173 \mathrm{~K}\right)$. At RT the magnetization did not drop to zero, and the hysterezis curves at RT (see Section 3.5.3 Hysteresis Loops subsection show that the reason for that is the presence of a ferromagnetic component, which we attribute to the phase $\alpha^{\prime}$.
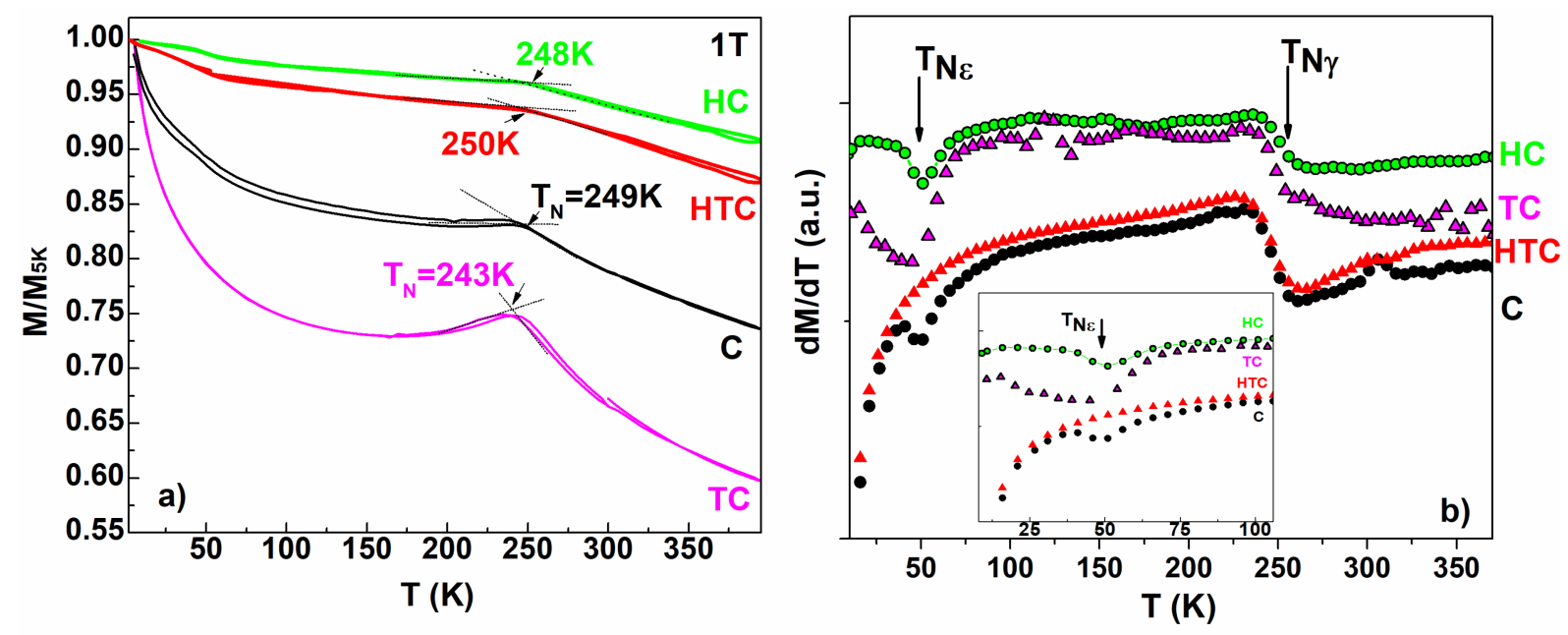

Figure 7. (a) The thermo-magnetic measurements at low temperature in $1 \mathrm{~T}$ applied magnetic field on all investigated samples. (b) The first derivative of magnetization $\mathrm{dM} / \mathrm{dT}$.

After a full heating-cooling circle, the measured temperature dependent magnetization shows a narrow hysteresis which is considered to depend mainly on the spin transition and interfacial effects [45]. The shape and area of this hysteresis differs from one sample to another due to different structure and morphology.

\subsubsection{High Temperature Thermo-Magnetic Measurements}

As already observed for the DSC measurements, the in situ investigations at high temperatures are in fact thermal treatments. Austenite reversion from $\varepsilon$ during the heating takes place on a large temperature interval for sample C (Figure 8a,c). This phenomenon is evidenced by the slightly decrease of magnetization in $\mathrm{M}(\mathrm{T})$ curves (see Figure 8c), being obvious also in the DSC signal. The temperature increase favors the atoms diffusion and apart from the $\alpha^{\prime}-\gamma$ transformation (taking place in the interval 750-800 K) and a new $\delta$ cubic phase grow, as the XRD pattern shows. The reversal martensitic transformation of TC 
sample indicated by temperature dependence of magnetization in Figure 8d) undergoes a two-steps process at high temperature: the $\varepsilon-\gamma$ transition associated with increased magnetization at $810 \mathrm{~K}$, and the $\alpha^{\prime}-\gamma$ transition associated with the $880 \mathrm{~K}$ peak. The different behavior of the TC sample, compared with $C$, is due to the thermo-mechanical training process which depletes the martensite in Mn pushing the reverse transformation towards higher temperatures. Moszner et al. [46], show that the heated alloys undergo a long-range, temperature-controlled diffusion mechanism which generate zones depleted in $\mathrm{Mn}$ in $\alpha^{\prime}$-martensite regions at the end of the first stage of reversion, and a second reversion stage: the $\alpha^{\prime}-\gamma \mathrm{MT}$, at higher temperatures. However, in the latter case, austenite reversion can be driven by both long-range and an interface-controlled mechanism. The same behavior was reported in $[23,47]$. At temperatures higher than $925 \mathrm{~K}$, both the HTC and $\mathrm{HC}$ samples become paramagnetic.
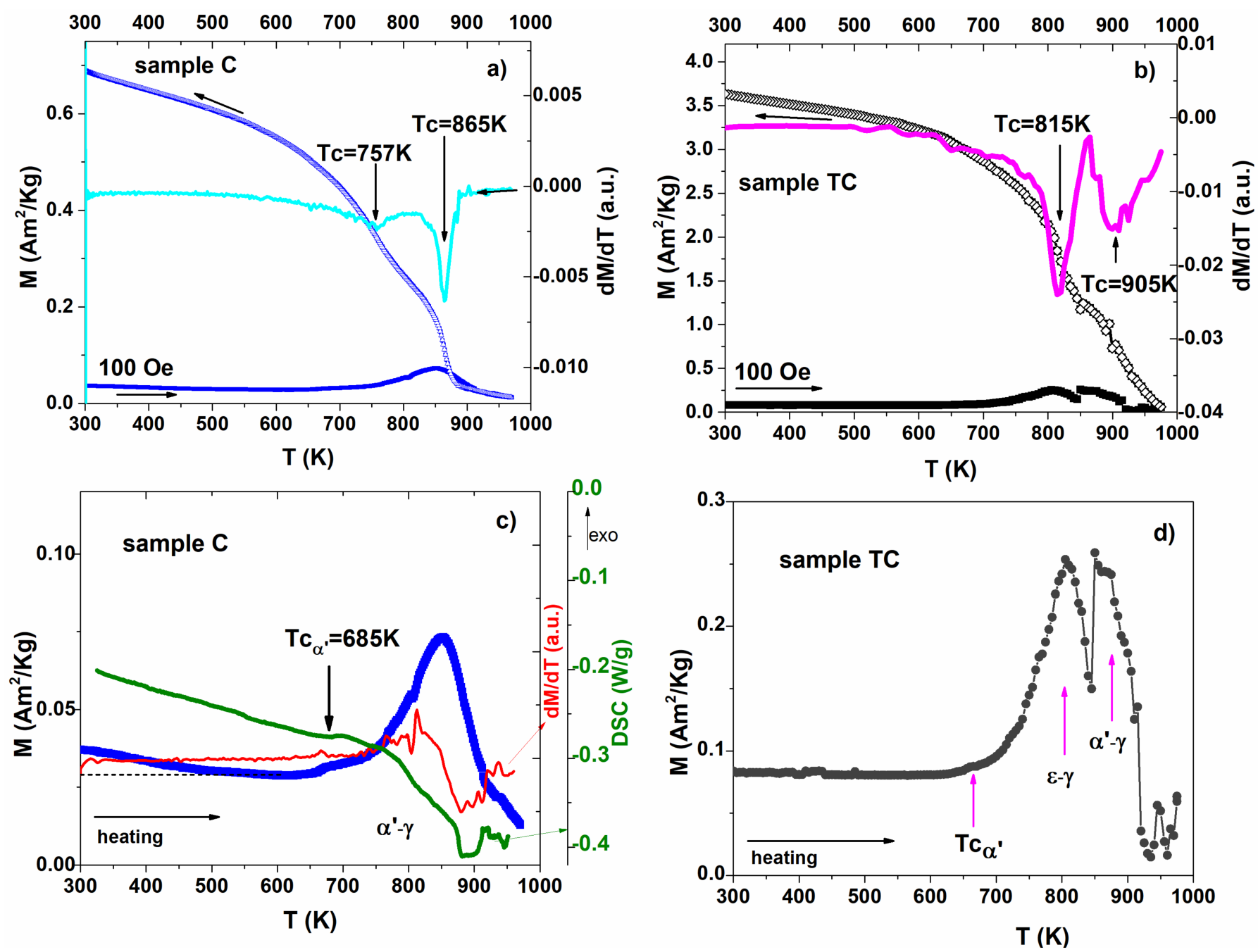

Figure 8. At high temperatures for (a) sample C and (b) sample TC; (c) Magnetization behavior superposed with DSC scan and $\mathrm{dM} / \mathrm{dT}$ on the heating the sample $\mathrm{C} ;(\mathbf{d}) \mathrm{M}(\mathrm{T})$ on heating of sample TC.

At the heating towards $975 \mathrm{~K}, \mathrm{HTC}$ sample also shows the segregation of a hightemperature phase above $940 \mathrm{~K}$. The Curie temperature $(\mathrm{Tc}=685 \mathrm{~K})$ of the $\alpha^{\prime}$ phase was evaluated from the $\mathrm{dM} / \mathrm{dT}$ data and is the same for both samples.

When cooled, both samples show an increase of magnetization suggesting that the new phase is ferromagnetic. From the $\mathrm{dM} / \mathrm{dT}$ data one can calculate the Curie temperatures from Figure $8 \mathrm{a}, \mathrm{b}$. The thermal treatment consisted in slowly heating up the sample to $975 \mathrm{~K}(2 \mathrm{~K} / \mathrm{min})$ followed by cooling, with a short dwelling time at high temperatures. As a result, the new $\delta$ phase did not have time to grow/stabilize homogenously in the sample, 
which might explain the presence of two Tc temperatures that might belong to two phases with slightly different compositions. The Curie temperatures are higher for the TC sample due to the lower Mn content in the newly formed cubic phase [23,46,47].

\subsubsection{Hysteresis Loops}

The hysteresis curves (Figure 9) for the $\mathrm{C}$ and TC samples, measured at $5 \mathrm{~K}$ and at RT, show an overlapping odd paramagnetic and ferromagnetic behavior. This is supported by the XRD results which show at RT the HSHPV induced $\varepsilon$ martensite, the $\gamma$ austenite, but also the $\alpha^{\prime}$ martensite.
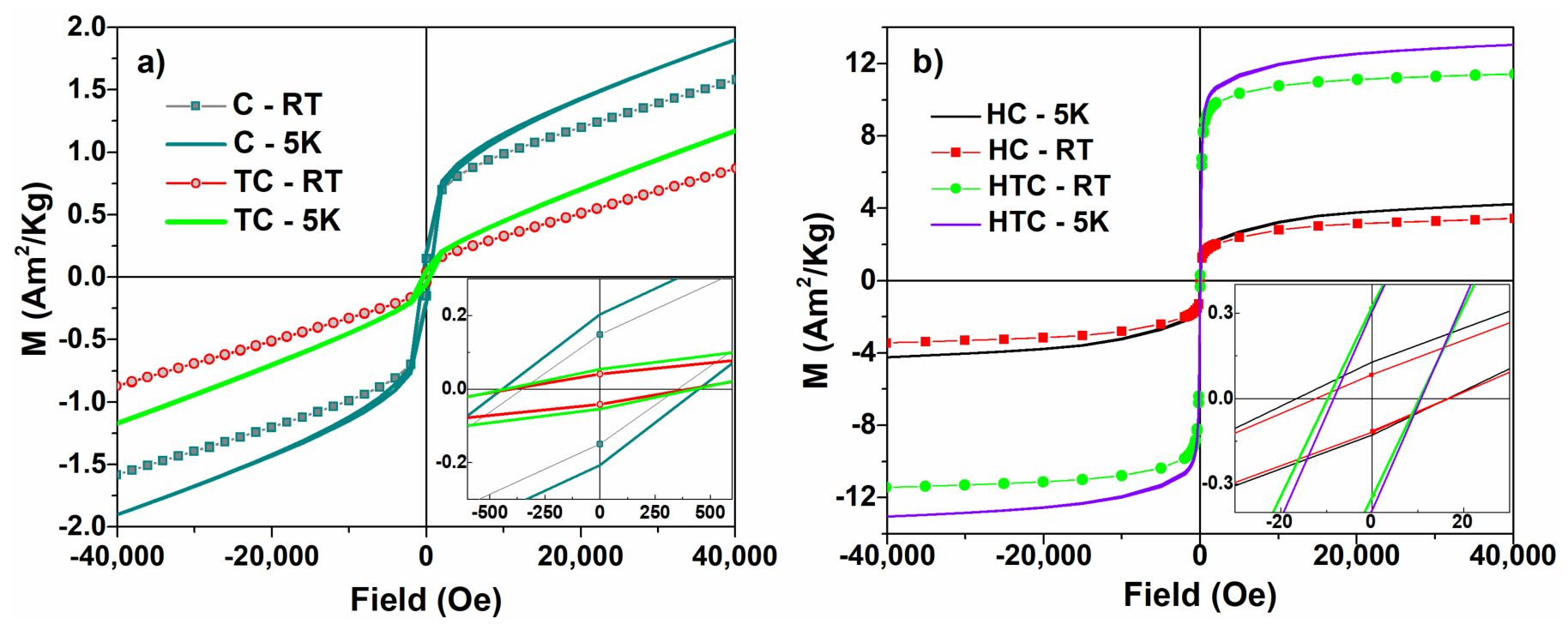

Figure 9. The hysteresis loops recorded at $5 \mathrm{~K}$ and $300 \mathrm{~K}$ for (a) $\mathrm{C}$ and TC samples; (b) the same for HC and HTC samples.

The paramagnetic behavior is due to the $\gamma$ austenite and the $\varepsilon$ martensite (with $\mathrm{T}_{\mathrm{N}}$ approx. $50 \mathrm{~K}$-see Figure $7 \mathrm{~b}$ ). The ferromagnetic component can be attributed to the $\alpha^{\prime}$ martensite which has a high magnetic order-disorder transition temperature $(680 \mathrm{~K}$ estimated $\mathrm{dM} / \mathrm{dT}$ on heating for both samples measured at high temperatures-Figure $8 \mathrm{c}, \mathrm{d}$ ).

After high temperature in situ thermal treatments the saturation magnetization reaches about $3.4 \mathrm{emu} / \mathrm{g}$ for the HC samples and $11.4 \mathrm{emu} / \mathrm{g}$ for the HTC sample. Instead, the coercivity decreases from 360 Oe for the $\mathrm{C}$ sample to only 14 Oe for the TC sample, respectively, from 400 Oe for the HC sample to 10 Oe in HTC sample. The magnetic behavior of the HC and HTC samples become soft magnetic, due to the segregation and growth of the $\delta$ ferromagnetic cubic phase to the detriment of the ferromagnetic $\alpha^{\prime}$ phase, but also due to the paramagnetic $\gamma$ si $\varepsilon$ phases. The values are in agreement with [47], which reported a saturation magnetization of only $3 \mathrm{emu} / \mathrm{g}$ lower for an alloy with $17.6 \mathrm{wt} . \% \mathrm{Mn}$, and also in agreement with [48] which measured magnetic saturation values at room temperature of $11.32 \mathrm{emu} / \mathrm{g}$ for Fe-30Mn-6Si (wt. \%) alloy and $18.34 \mathrm{emu} / \mathrm{g}$ for Fe30Mn-6Si-5Cr (wt.\%) alloy.

\subsection{Transport Properties}

The transport properties of shape memory alloys depend on the electronic spectrum, electron-magnon, electron-phonon, spin-orbit couplings, polarization rotation and also on the crystal structure and phase transformations [49]. In ferromagnetic alloys SMAs the phase equilibrium is influenced by the shape of the $3 \mathrm{~d}$ electron state density in the vicinity of the Fermi level, while the Jahn-Teller effect seems to be at the origin of the structural phase transition [50]. In this context, the transport properties of ferromagnetic shape memory alloys during the MT pose an intricate problem, as the hysteretic anomaly of the resistivity (observed also on our samples) around MT suggests [8]. 
The low temperature dependence of resistivity for samples $C$ and TC (shown in Figure 10) is influenced mainly by the antiferromagnetic ordering of the spins below $\mathrm{T}_{\mathrm{N}}=244 \mathrm{~K}$, specific to the austenitic $\gamma$ phase [43]. On cooling, until the antiferromagnetic order sets in, the resistivity has a metallic behavior, but at lower temperatures, an abnormal increase of the resistivity is observed. According to [51] this behavior is explained to a large extent by two factors: an effective reduction in the number of conduction electrons, originating from a truncation of the Fermi surface due to the antiferromagnetic energy gap below $T_{N}$, and the increase of the magnetic scattering caused by the occurrence of a localised net moment on Fe atoms. The Neel temperature $(244 \mathrm{~K})$ determined from the thermo-resistivity measurements; Figure 10 is consistent with the temperature resulting from the thermomagnetic measurements (Figure 7a). Noteworthy, the transport properties of the $\mathrm{Fe}_{57} \mathrm{Mn}_{27} \mathrm{Si}_{11} \mathrm{Cr}_{5}$ (at \%) alloy processed via HSHPT agree well with the specific behavior of Fe-Mn-Si alloys reported in literature [51,52].
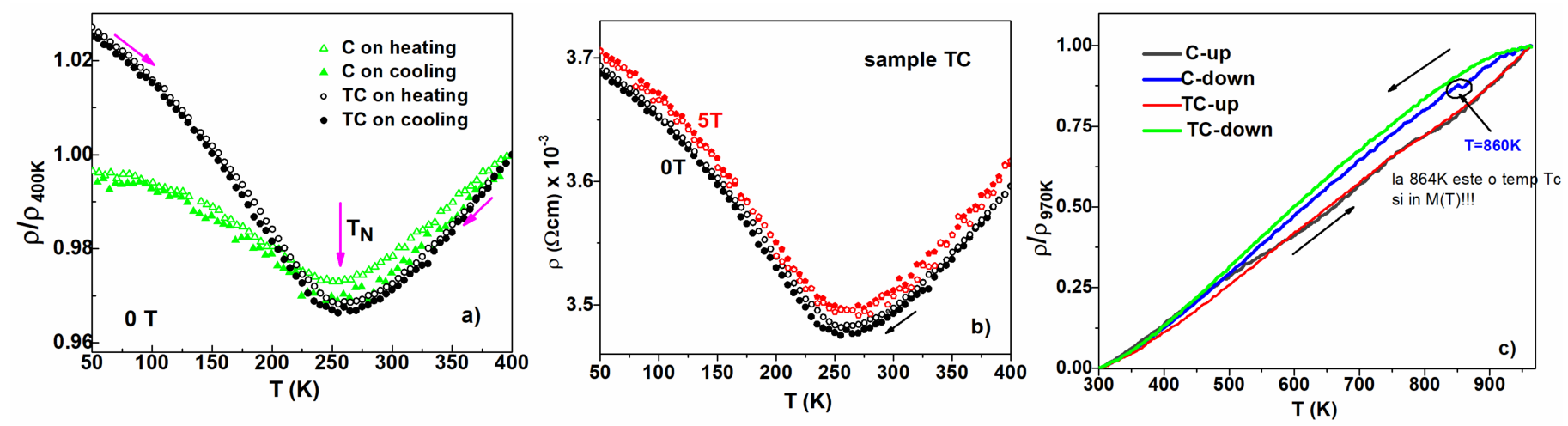

Figure 10. (a) normalized temperature dependence of the resistivity for samples $C$ and TC; (b) resistivity variation with temperature in zero and $5 \mathrm{~T} ;(\mathbf{c})$ the variation of resistance with temperature at high temperature.

The presence of a small thermal hysteresis is also remarkable. As in the case of the temperature dependence of the magnetization, it can be associated with the presence of the martensitic phase $\alpha^{\prime}$.

If in other types of SMAs the resistivity decreases when the magnetic field is applied $[8,53]$, in the FeMnSiCr alloy processed by HSHPT technique, there is an increase of the resistivity when a magnetic field is applied-Figure 10b. Thermo-resistivity measurements performed at high temperatures from Figure 10c reveal a metallic behavior for both samples: the resistivity decreases linearly on cooling due to the phonon scattering [20].

\section{Conclusions}

The effects of HSHPT and in situ thermal treatment on the properties of $\mathrm{Fe}_{57} \mathrm{Mn}_{27} \mathrm{Si}_{11} \mathrm{Cr}_{5}$ (at \%) alloy were investigated. Microstructural investigations show that HSHPT produces a grain refinement with a wide grain size range, the appearance of needle-shaped $\varepsilon$-martensite ( $50 \mathrm{~nm}$ to $120 \mathrm{~nm}$ wide) and various defects. The crystalline structure of the HSHPT samples consists mainly of the austenite $\gamma$ with $\varepsilon$ and $\alpha^{\prime}$ martensite secondary phases, while the thermal treatments promote a bcc-ferrite type phase with traces of $\gamma$ and $\varepsilon$. As an effect, the temperature dependence of magnetization shows at low temperature an anomaly specific to the antiferromagnetic transition of the austenitic $\gamma$-phase $(\sim 244 \mathrm{~K})$ in all samples, which correlates to the thermo-resistivity measurements that show a metallic behavior down to $T_{N}$ and an anomalous increase below $T_{N}$ mainly due to the phonon scattering on spins. At room temperature, the overall behavior of magnetisation suggests the existence of two overlaying magnetic phases: the paramagnetic one (associated with austenite and $\varepsilon$ martensite) and a magnetic ordered phase which gives a finite magnetization at RT, associated with $\alpha^{\prime}$ martensite. High temperature measurements act as in situ thermal treatments and lead to the formation of a $\delta$ bcc-ferrite type phase with ferromagnetic behavior, reflected by the temperature dependence of the magnetization. 
Author Contributions: Conceptualization, C.G. and F.T.; methodology, C.G. and F.T.; software, G.G.; validation, C.G., G.G., F.T., B.P., M.B. and L.-G.B.; investigation, C.G., G.G., F.T., B.P., M.B. and L.-G.B.; resources, C.G., G.G. and F.T.; data curation, C.G. and F.T.; writing-original draft preparation, C.G., B.P. and F.T.; writing-review and editing, C.G., F.T. and B.P.; visualization, C.G., G.G., F.T., B.P., M.B. and L.-G.B.; supervision, C.G. and F.T.; project administration, G.G. and F.T.; funding acquisition, G.G. and F.T. All authors have read and agreed to the published version of the manuscript.

Funding: CNCS/CCCDI-UEFISCDI projects number PN-III-P2-2.1-PED-2019-1276, contract no. 324PED/2020, PN-III-P2-2.1-PED-2019-3453 contract no. 493PED/2020 within PNCDI III funded by the Romanian Ministry of Research Innovation and Digitalization.

Institutional Review Board Statement: Not applicable.

Informed Consent Statement: Not applicable.

Data Availability Statement: Data can be provided by the corresponding author upon reasonable request.

Acknowledgments: The authors thank to Andrei Galatanu for upgrade of soft for electric transport measurements performed up to $975 \mathrm{~K}$ in controlled atmosphere.

Conflicts of Interest: The authors declare no conflict of interest.

\section{References}

1. Mahesh, K.K.; Braz Fernandes, F.M.; Gurau, G. Stability of thermal-induced phase transformations in the severely deformed equiatomic Ni-Ti alloys. J. Mater. Sci. 2012, 47, 6005. [CrossRef]

2. Kishia, Y.; Craciunescu, C.; Sato, M.; Okazaki, T.; Furuya, Y.; Wuttig, M. Microstructures and magnetic properties of rapidlysolidified CoNiGa ferromagnetic shape memoryalloys. J. Mag. Mag. Mater. 2003, 262, L186-L191. [CrossRef]

3. Samothrakitis, S.; Buhl Larsen, C.; Woracek, R.; Heller, L.; Kopeček, J.; Gerstein, G.; Maier, H.J.; Rameš, M.; Tovar, M.; Šittner, P.; et al. A multiscale study of hot-extruded CoNiGa ferromagnetic shape-memory alloys. Mater. Des. 2020, 196, 109118. [CrossRef]

4. Tejeda-Cruz, A.; Alvarado-Hernández, F.; Soto-Parra, D.E.; Ochoa-Gamboa, R.; Castillo-Villa, P.O.; Flores-Zúniga, H.; Haro-Rodriguez, S.; Santos-Beltrán, A.; Ríos-Jara, D. Microstructure, transformation temperatures, hardness and magnetic properties of Co36.4+xNi33.3-xGa30.3 ferromagnetic SMA. J. Alloys Compd. 2010, 499, 183-186. [CrossRef]

5. Suru, M.G.; Paraschiv, A.L.; Lohan, N.M.; Pricop, B.; Ozkal, B.; Bujoreanu, L.G. Loading Mode and Environment Effects on Surface Profile Characteristics of Martensite Plates in Cu-Based SMAs. J. Mater. Eng. Perf. 2014, 23, 2669. [CrossRef]

6. Gutiérrez, J.; Barandiarán, J.M.; Lázpita, P.; Seguí, C.; Cesari, E. Magnetic properties of a rapidly quenched Ni-Mn-Ga shape memory alloy. Sens. Actuators A Phys. 2006, 129, 163. [CrossRef]

7. Dunand, D.C.; Müllner, P. Size effects on magnetic actuation in Ni-Mn-Ga shape-memory alloys. Adv. Mater. 2011, 23, 216. [CrossRef] [PubMed]

8. Barandiarán, J.M.; Chernenko, V.A.; Lázpita, P.; Gutiérrez, J.; Feuchtwanger, J. Effect of martensitic transformation and magnetic field on transport properties of Ni-Mn-Ga and Ni-Fe-Ga Heusler alloys. Phys. Rev. B 2009, 80, 104404. [CrossRef]

9. Chernenko, V.A.; Oikawa, K.; Cheielus, M.; Besseghini, S.; Villa, E.; Albertini, F.; Roghi, L.; Paoluzi, A.; Mullner, P.; Kainuma, R.; et al. Properties of co-alloyed Ni-Fe-Ga ferromagnetic shape memory alloys. J. Mater. Eng. Perfor 2009, 18, 548. [CrossRef]

10. Gulyaev, A. Some Features of $\gamma-\varepsilon$ Martensitic Transformation and Shape MemoryEffect in Fe-Mn-Si Based alloys. J. Phys. IV Colloq. 1995, C8, 469-474.

11. Gu, Q.; Van Humbeeck, J.; Delaey, L. A review on the martensitic transformation and shape memory effect in Fe-Mn-Si alloys. J. Phys. IV Colloq. 1994, C3, 135-144. [CrossRef]

12. Sánchez-Alarcos, V.; Recarte, V.; Pérez-Landazábal, J.I.; González, M.A.; Rodríguez-Velamazán, J.A. Effect of Mn addition on the structural and magnetic properties of Fe-Pd ferromagnetic shape memory alloys. Acta Mater. 2009, 57, 4224. [CrossRef]

13. Hayashi, R.; Murray, S.J.; Marioni, M.; Allen, S.M.; O'Handley, R.C. Magnetic and mechanical properties of FeNiCoTi magnetic shape memory alloy. Sens. Actuators A Phys. 2000, 81, 219. [CrossRef]

14. Huang, P.; Peng, H.; Wang, S.; Zhou, T.; Wen, Y. Relationship between martensitic reversibility and different nano-phases in a FeMnAlNi shape memory alloy. Mater. Charact. 2016, 118, 22-28. [CrossRef]

15. Koster, M.; Lee, W.J.; Schwarzenberger, M.; Leinenbach, C. Cyclic deformation and structural fatigue behavior of an FE-Mn-Si shape memory alloy. Mater. Sci. Eng. A 2015, 637, 29-39. [CrossRef]

16. Stanford, N.; Dunne, D.P. Effect of Si on the reversibility of stress-induced martensite in Fe-Mn-Si shape memory alloys. Acta Mater. 2010, 58, 6752-6762. [CrossRef]

17. Cladera, A.; Weber, B.; Leinenbach, C.; Czaderski, C.; Shahverdi, M.; Motavalli, M. Iron-based shape memory alloys for civil engineering structures: An overview. Constr. Build. Mater. 2014, 63, 281-293. [CrossRef]

18. Stanford, N.; Dunne, D.P. Effect of second-phase particles on shape memory in Fe-Mn-Si-based alloys. Mater. Sci. Eng. A 2007, 454-455, 407-415. [CrossRef] 
19. Fuster, V.; Druker, A.V.; Baruj, A.; Malarría, J.; Bolmaro, R. Characterization of phases in an Fe-Mn-Si-Cr-Ni shape memory alloy processed by different thermomechanical methods. Mater. Charact. 2015, 109, 128-137. [CrossRef]

20. Qin, Z.; Yu, M.; Zhang, Y. Neel transition and $\gamma-\varepsilon$ transformation in polycrystalline Fe-Mn-Si shape memory alloys. J. Mater. Sci. 1996, 31, 2311-2315.

21. Eskil, M.; Ceylan, M. Characterization of phase transformations and shape memory behavior of Fe-27.79Mn-2.72Si (wt $\%$ ) alloy by thermomechanical and thermal treatments. J. Mater. Sci. 2009, 44, 3633-3642. [CrossRef]

22. Bracke, L.; Kestensa, L.; Penning, J. Transformation mechanism of $\alpha^{\prime}$-martensite in an austenitic Fe-Mn-C-N alloy. Scr. Mater. 2007, 57, 385-388. [CrossRef]

23. Souza Filho, I.R.; Kwiatkowski da Silva, A.; Sandim, M.J.R.; Ponge, D.; Gault, B.; Sandim, H.R.Z.; Raabe, D. Martensite to austenite reversion in a high-Mn steel: Partitioning- dependent two-stage kinetics revealed by atom probe tomography, in-situ magnetic measurements and simulation. Acta Mater. 2019, 166, 178-191. [CrossRef]

24. Greer, J.R.; De Hosson, J.T.M. Plasticity in small-sized metallic systems: Intrinsic versus extrinsic size effect. Prog. Mater. Sci. 2011, 56, 654-724. [CrossRef]

25. Glezer, A.M.; Sundeev, R.V. General view of severe plastic deformation in solid state. Mater. Lett. 2015, 139, 455-457. [CrossRef]

26. Druker, A.V.; Baruj, A.; Isola, L.; Fuster, V.; Malarría, J.; Bolmaro, R. Gaining flexibility in the design of microstructure, texture and shape memory properties of an Fe-Mn-Si-Cr-Ni alloy processed by ECAE and annealing. Mater. Des. 2016, 107, 153-162. [CrossRef]

27. Panigrahi, A.; Sulkowski, B.; Waitz, T.; Ozaltin, K.; Chrominski, W.; Pukenas, A.; Horky, J.; Lewandowska, M.; Skrotzki, W.; Zehetbauer, M. Mechanical properties, structural and texture evolution of biocompatible Ti-45Nb alloy processed by severe plastic deformation. J. Mech. Behav. Biomed. Mater. 2016, 62, 93-105. [CrossRef]

28. Kang, J.Y.; Kim, J.G.; Kim, S.K.; Chin, K.-G.; Lee, S.; Kim, H.S. Outstanding mechanical properties of high-pressure torsion processed multiscale TWIP-cored three layer steel sheet. Scr. Mater. 2016, 123, 122-125. [CrossRef]

29. An, X.H.; Lin, Q.Y.; Sha, G.; Huang, M.X.; Ringer, S.P.; Zhu, Y.T.; Liao, X.Z. Microstructural evolution and phase transformation in twinning-induced plasticity steel induced by high-pressure torsion. Acta Mater. 2016, 109, 300-313. [CrossRef]

30. López, G.A.; López-Ferreño, I.; Kilmametov, A.R.; Breczewski, T.; Straumal, B.B.; Baretzky, B.; Nó, M.L.; Juan, J.S. Severe plastic deformation on powder metallurgy $\mathrm{Cu}-\mathrm{Al}-\mathrm{Ni}$ shape memory alloys. Mater. Today Proc. 2015, 2, S747-S750. [CrossRef]

31. Zhang, W.; Wen, Y.-H.; Li, N.; Huang, S.-K. Remarkable improvement of recovery stress of Fe-Mn-Si shape memory alloy fabricated by equal channel angular pressing. Mater. Sci. Eng. A 2007, 454-455, 19-23. [CrossRef]

32. Gurău, G.; Gurău, C.; Potecaşu, O.; Alexandru, P.; Bujoreanu, L.G. Novel high speed high pressure torsion technology for obtaining Fe-Mn-SiCr shape memory alloy active elements. J. Mater. Eng. Perform. 2014, 23, 2396-2402. [CrossRef]

33. Gurau, G.; Gurau, C.; Fernandes, F.M.B.; Bujoreanu, L.G. A comparative study of austenitic structure in NiTi and Fe based shape memory alloys after severe plastic deformation. Mater. Today Proc. 2015, 2, S905-S908. [CrossRef]

34. Chowdhury, P.; Canadinc, D.; Sehitoglu, H. On deformation behavior of Fe-Mn based structural alloys. Mater. Sci. Eng. R Rep. 2017, 122, 1-28. [CrossRef]

35. AWAJI Materia Co., LTD. Japanese Site. Available online: http://www.awaji-m.jp/english/company/profile.html (accessed on 9 March 2017).

36. Karimi, M.; Toroghinejad, M.R.; Dutkiewicz, J. Nanostructure formation during accumulative roll bonding of commercial purity titanium. Mater. Charact. 2016, 122, 98-103. [CrossRef]

37. Nikulin, I.; Sawaguchi, T.; Ogawa, K.; Tsuzaki, K. Effect of $\gamma$ to $\varepsilon$ martensitic transformation on low-cycle fatigue behaviour and fatigue microstructure of Fee15Mne10Cre8NiexSi austenitic alloys. Acta Mater. 2016, 105, 207-218. [CrossRef]

38. Guerrero, L.M.; La Roca, P.; Malamud, F.; Baruj, A.; Sade, M. Composition effects on the fcc-hcp martensitic transformation and on the magnetic ordering of the fcc structure in Fe-Mn-Cr alloys. Mater. Des. 2017, 116, 127-135. [CrossRef]

39. Sari, U.; Kirindi, T.; Yýksel, M.; Agan, S. Influence of Mo and Co on the magnetic properties and martensitic transformation characteristics of a Fe-Mn alloy. J. Alloys Compd. 2009, 476, 160-163. [CrossRef]

40. Gebhardt, T.; Music, D.; Ekholm, M.; Abrikosov, I.A.; Von Appen, J.; Dronskowski, R.; Wagner, D.; Mayer, J.; Schneider, J.M. Influence of chemical composition and magnetic effects on the elastic properties of fcc Fe-Mn alloys. Acta Mater. 2011, 59, 1493-1501. [CrossRef]

41. Kim, Y.S.; Choi, E.; Kim, W.J. Characterization of the microstructures and the shape memory properties of the Fe-Mn-Si-Cr-Ni-C shape memory alloy after severe plastic deformation by differential speed rolling and subsequent annealing. Mater. Charact. 2018, 136, 12-19. [CrossRef]

42. Andersson, M.; Forsberg, A.; Agren, J. Martensitic and magnetic transformations in Fe-Mn-Si shape memory alloys. In Ecomaterials; Elsevier: Amsterdam, The Netherlands, 1994. [CrossRef]

43. Valeanu, M.; Filoti, G.; Kuncser, V.; Tolea, F.; Popescu, B.; Galatanu, A. Shape memory and associated properties in Fe-Mn-Si-based ribbons produced by melt-spinning. J. Magn. Magn. Mater. 2008, 320, e164-e167. [CrossRef]

44. Bouraoui, T.; Van Neste, A.; Dubois, B. Comparative Effects of Thermal Treatments on the Shape Memory Phenomenon of Fe-Mn-Si and Fe-Mn-Cr-Ni-Si Steels. J. Phys. IV Colloq. 1995, C8, 403-408. [CrossRef]

45. Wang, L.; Cui, Y.G.; Wan, J.F.; Zhang, J.H.; Rong, Y.H. Magnetic thermal hysteresis due to paramagnetic-antiferromagnetic transition in Fe-24.4Mn-5.9Si-5.1Cr alloy. AIP Adv. 2013, 3, 082126. [CrossRef] 
46. Moszner, F.; Povoden-Karadeniz, E.; Pogatscher, S.; Uggowitzer, P.J.; Estrin, Y.; Gerstl, S.S.A.; Kozeschnik, E.; Löffler, J.F. Reverse $\alpha^{\prime} \rightarrow \gamma$ transformation mechanisms of martensitic Fe-Mn and age-hardenable Fe-Mn-Pd alloy upon fast and slow continuous heating. Acta Mater. 2014, 72, 99-109. [CrossRef]

47. Souza Filho, I.R.; Sandima, M.J.R.; Cohen, R.; Nagaminec, L.C.C.M.; Sandima, H.R.Z.; Raabe, D. Magnetic properties of a 17.6 Mn-TRIP steel: Study of strain-induced martensite formation, austenite reversion, and athermal $\alpha^{\prime}$-formation. J. Mag. Mag. Mater. 2019, 473, 109-118. [CrossRef]

48. Nevin Balo, S. A Comparative Study on Crystal Structure and Magnetic Properties of Fe-Mn-Si and Fe-Mn-Si-Cr Alloys. J. Supercond. Nov. Magn. 2013, 26, 1085-1088. [CrossRef]

49. Chernenko, V.A.; Cesari, E.; Kokorin, V.V.; Vitenko, I.N. The development of new ferromagnetic shape memory alloys in Ni-Mn-Ga system. Scr. Metall. Mater. 1995, 33, 1239-1244. [CrossRef]

50. Opahle, I.; Koepernik, K.; Nitzsche, U.; Richter, M. Jahn-Teller-like origin of the tetragonal distortion in disordered Fe-Pd magnetic shape memory alloys. Appl. Phys. Lett. 2009, 94, 072508. [CrossRef]

51. Zhang, Y. A study on the Neel transition and the Kondo-like effect of y-Fe-Mn-Si alloys. J. Phys. F Met. Phys. 1988, 18, L229-L235. [CrossRef]

52. Zhang, Y.S.; Lu, X.; Tian, X.; Qin, Z. Compositional dependence of the Néel transition, structural stability, magnetic properties and electrical resistivity in Fe-Mn-Al-Cr-Si alloys. Mater. Sci. Eng. A 2002, 334, 19-27. [CrossRef]

53. Tolea, F.; Tolea, M.; Sofronie, M.; Popescu, B.; Crisan, A.; Leca, A.; Valeanu, M. Specific changes in the magnetoresistance of $\mathrm{Ni}-\mathrm{Fe}-\mathrm{Ga}$ Heusler alloys induced by $\mathrm{Cu}, \mathrm{Co}$ and $\mathrm{Al}$ substitutions. IEEE Trans. Magn. 2015, 51, 2500404. [CrossRef] 